\title{
Poly(acrylamide-co-acrylic acid) synthesized, moxifloxacin drug-loaded hydrogel: Characterization and evaluation studies
}

\author{
Madhusudana Thippeswamy¹ (D), Mamatha Ganjeenahalli Puttagiddappa²* (D), Demappa Thippaiah ${ }^{3}$ (D), Nayak Devappa \\ Satyanarayan ${ }^{1}$ \\ ${ }^{1}$ Department of Pharmaceutical Chemistry, Kuvempu University, P.G. Centre, Kadur-577548, Karnataka, India. \\ ${ }^{2}$ Department of Chemistry, Davangere University, Shivagangotri, Davangere-577002, Karnataka, India. \\ ${ }^{3}$ Department of Polymer Science, University of Mysore, Sir M.V.P.G. Centre, Mandya-571402, Karnataka, India.
}

\section{ARTICLE INFO \\ Received on: 11/06/2021 \\ Accepted on: 11/08/2021 \\ Available Online: 05/12/2021}

\section{Key words:}

Smart hydrogel, acrylic acid, acrylamide, drug delivery, moxifloxacin.

\begin{abstract}
Sustained and controlled drug release has become the most attractive research work for obtaining a better drug delivery system with reliability, performance, and safe drug release in the modern pharmaceutical drug delivery design. In this view, different polymers in controlled drug delivery applications are very useful. Therefore, using copolymerization by free-radical crosslinking and methylenebisacrylamide as the crosslinker with potassium persulfate and sodium metabisulfite as initiators, we synthesized poly(acrylamide-co-acrylic acid) hydrogels. The synthesized hydrogels were characterized by FTIR, TGA, SEM, swelling, and in-vitro drug release studies which were carried out. The hydrogel swelling analysis was analyzed using buffer solutions at varying $\mathrm{pH}$ and temperature levels. Drug release was investigated using moxifloxacin hydrochloride as a model drug. The drug release data indicate that after 5 hours, the drug release was found to be $18 \%$ at acidic $\mathrm{pH} 1.2$ and $99 \%$ at alkaline $\mathrm{pH} 7.4$, and it followed the Higuchi model.
\end{abstract}

\section{INTRODUCTION}

Hydrogels are polymer networks capable of carrying more water or biological fluid that are hydrophilic in nature. Due to the existence of physical or chemical crosslinks, polymer networks are formed by homopolymers or copolymers of an insoluble nature. These hydrogels have a thermodynamic affinity for water, which allows them to expand in an aqueous solution (Peppas and Khare, 1993). These hydrogels have a broader range of applications, especially in the medical and pharmaceutical fields (Peppas and Langer, 1994; Ratner and Hoffman, 1976; Varaprasad et al., 2017). The presence of extra water content and softness in the hydrogel is similar to the natural living tissue than any other synthetic biomaterial (Ratner and Hoffman, 1976). Also, because of the presence of extra water content, hydrogels have a

\footnotetext{
"Corresponding Author

G. P. Mamatha, Department of Chemistry, Davangere University, Shivagangotri, Davangere-577002, Karnataka, India., India. E-mail: mamatha_gp2005@rediffmail.com
}

biocompatibility quality. Hydrogels can also be used as biosensor membranes, drug delivery systems, artificial skin fabrics, linings for artificial hearts, and contact lenses (Moghimi and Hunter, 2000; Peppas, 1997).

In response to slight changes in environmental parameters such as ionic pressure, $\mathrm{pH}$, and temperature, hydrogels can show rapid volume changes known as stimuli-responsive materials. In smart hydrogels, stimulus-responsive polymers play a major role, and these hydrogels are used in separation processes for industrial applications as potential economic alternatives to conventional separation processes (Shah and Patel, 2014). Regulated permeability variations of sensitive gels may accomplish the charge or size-selective separations. The magnetic or electric field reveals powerful improvements in their swelling behavior, in addition to the temperature and $\mathrm{pH}$ sensitivity of the swelling behavior.

The copolymer, which consists of acrylic acid (AAC) and acrylamide (AAM) units, is poly(AAM-co-AAC). A charge, hydrogen-bonding capacity, and adequate polarity for hydration are provided by the hydrophilic carboxylic acid and amide moieties in the polymer backbone. The copolymer is very 
sensitive to $\mathrm{pH}$ and temperature; so, in response to changes in $\mathrm{pH}$ and temperature, this hydrogel shows a shift in swelling behavior (Vinu and Madras, 2008).

Moxifloxacin is classified as a Biopharmaceutical Classification System (BCS) class I drug due to its high solubility and high permeability. If a drug substance has an absorption rate of $85 \%$ in humans, it is characterized as "highly permeable". We chose moxifloxacin as a model drug because it has a rapid and nearly complete absorption in humans, with an absolute bioavailability of around 90\% (Charoo et al., 2020).

A class of fourth-generation fluoroquinolone antibiotic drugs is moxifloxacin hydrochloride (Fig. 1). A bulk side chain in the $\mathrm{C}-7$ position and a methoxy group in the $\mathrm{C}-8$ position is present in the structure (Biedenbach and Jones, 1996; Dalhoff et al., 1996; Davis and Bryson, 1994). This antibiotic property is effective against both Gram-positive and Gram-negative bacteria. The mechanism of action of moxifloxacin is involved in the inhibition of topoisomerase IV and DNA gyrase enzymes essential for the replication, repair, and transcription of bacterial DNA (Imming et al., 2006; Reece and Maxwell, 1991; Pestova et al., 2000).

The current study targeted the synthesis of poly(AAM-co$\mathrm{AAC}$ ) hydrogels by using AAM and AAC as monomers for varying crosslinkers with sodium metabisulfite (SMBS) and potassium persulfate as initiators. AAC allows water to swell further and AAM increases the hydrogel mechanical strength, so these hydrogels have strong mechanical and swelling potential. The presence of amide and acidic groups causes $\mathrm{pH}$ sensitivity in the polymer chain. As a model drug, the drug release analysis was carried out using

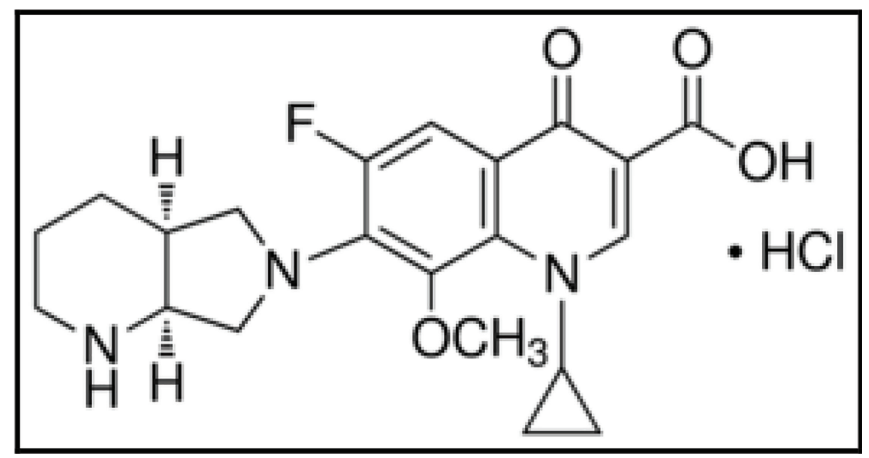

Figure 1. Molecular composition of moxifloxacin hydrochloride. moxifloxacin hydrochloride. In this study, the synthesized hydrogel is used to controlled release of the moxifloxacin drug.

\section{Materials and Methods}

\section{Materials}

AAC, MBA, potassium persulfate (PPS), AAM, sodium hydroxide, and potassium dihydrogen orthophosphate were received from Sd Fine Chem Limited (SDFCL), Mumbai, India. Hydrochloric acid and disodium hydrogen phosphate anhydrous were from Merck, Mumbai, India. SMBS was obtained from Avra Synthesis Pvt Ltd, Hyderabad, India. Moxifloxacin hydrochloride was received as a gift sample from Micro Labs Limited, Bangalore, India.

\section{Hydrogel synthesis}

The poly(AAM-co-AAC) hydrogel was synthesized in a glass vial using free radical initiators of SMBS and PPS by dissolving in distilled water to generate free radicals. Then, AAC and AAM monomers were added and allowed to blend for 10 minutes at an ambient temperature; then crosslinker MBA was added with uniform stirring. Then, this blend was placed in a water bath $\left(80^{\circ} \mathrm{C}\right)$ for 1 hour until gel formation. After gel formation, it was washed with distilled water for 24 hours to eliminate unreacted constituents and eventually dried for 24 hours in the hot air oven at $50^{\circ} \mathrm{C}$ and stored in a closed container to avoid moisture absorbance.

\section{Characterization}

\section{FTIR analysis}

To determine the molecular interactions and structure, moxifloxacin hydrochloride, synthesized hydrogel, and moxifloxacin-loaded hydrogel samples were analyzed using the Fourier Transform Infrared Spectroscopy (FTIR) instrument (Shimadzu, IRAffinity 1S FTIR, Japan).

\section{TGA analysis}

In a thermogravimetric analyzer (Perkin Elmer, STA 6000 , USA), Thermogravimetric analysis (TGA) of the synthesized hydrogel was carried out. TGA was carried out by increasing the heat flow rate under the nitrogen atmosphere to $20^{\circ} \mathrm{C} /$ minute.

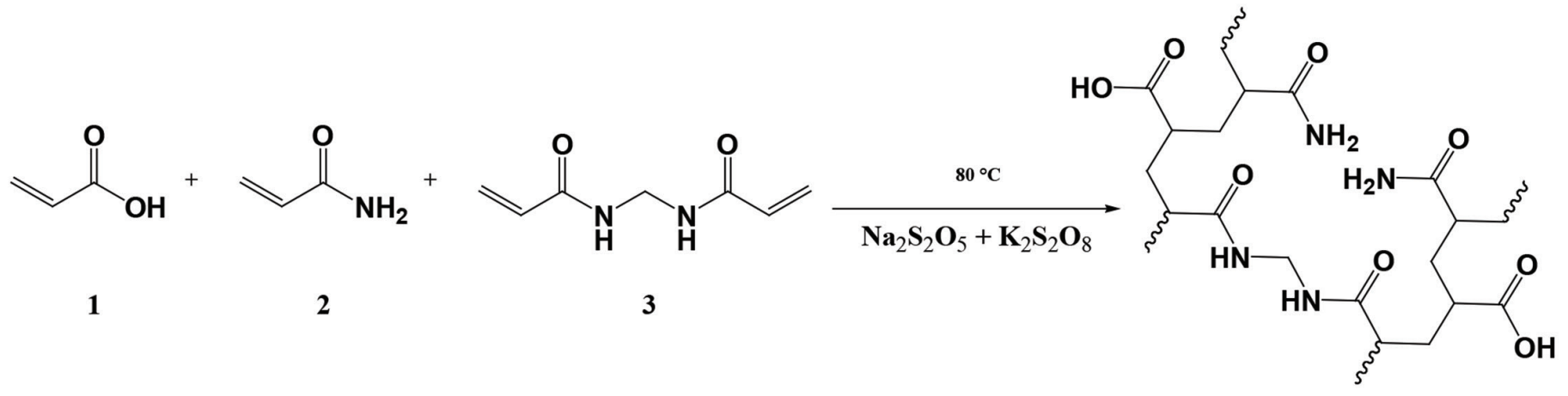




\section{SEM study}

To study the surface morphology of dried hydrogels, a scanning electron microscope was used. Using an Scanning electron microscope (SEM) (Zeiss, LS15, Germany) instrument, the hydrogel composites were exposed and imaged.

\section{Swelling study}

The swelling ratio was measured over time periods at various temperatures and $\mathrm{pH}$ solutions. Using $\mathrm{HCl}$ and $\mathrm{NaOH}$ solutions, the $\mathrm{pH}$ solutions were prepared. The $\mathrm{pH}$ solutions for swelling were applied to a known mass of hydrogel samples. The wet mass of the swollen samples was removed at particular time intervals and the surface water was absorbed with filter paper to eliminate excess outer surface droplets, and then the swelling ratio was weighed and measured using Equation 1.

$$
\text { Swelling ratio }(\%)=\frac{W_{2}-W_{1}}{W_{1}} \times 100
$$
hydrogel.

where $W_{1}$ and $W_{2}$ are the initial and final weights of the

\section{Preparation of calibration curve}

The calibration curve was prepared using $100 \mathrm{mg} / 100$ $\mathrm{ml}$ of moxifloxacin hydrochloride stock solution. The stock solution was formulated using a phosphate buffer solution of $\mathrm{pH}$ 7.4 ; then the solutions of $2,4,6,8$, and $10 \mathrm{mg} / 1$ were prepared using the stock solution. The solutions from 200 to $400 \mathrm{~nm}$ were scanned using a spectrophotometer (Metash, UV-9000, China) and maximum absorption at $\lambda_{\max } 288 \mathrm{~nm}$ was reported to prepare a calibration curve.

\section{Drug-loading and drug release studies}

By soaking the dry hydrogel in the presence of a drugcarrying solution, the drug would be loaded into the hydrogel. Moxifloxacin hydrochloride was selected as a model drug for the study of drug release. To $100 \mathrm{ml}$ of moxifloxacin solution $(1 \mathrm{mg} / \mathrm{ml})$ in water, $0.1 \mathrm{~g}$ of dry hydrogel was added for drug loading. After 48 hours, the loaded hydrogels were weighed, and to prevent burst release, the loaded hydrogel was washed with ethanol and then placed in the vacuum oven for 24 hours to dry completely. The dried hydrogels were then weighed and the drug load was determined by using Equation (2). The in-vitro release efficiency of drug-loaded hydrogel in an acid buffer solution of pH 1.2 and phosphate buffer solution of $\mathrm{pH} 7.4$ was evaluated at
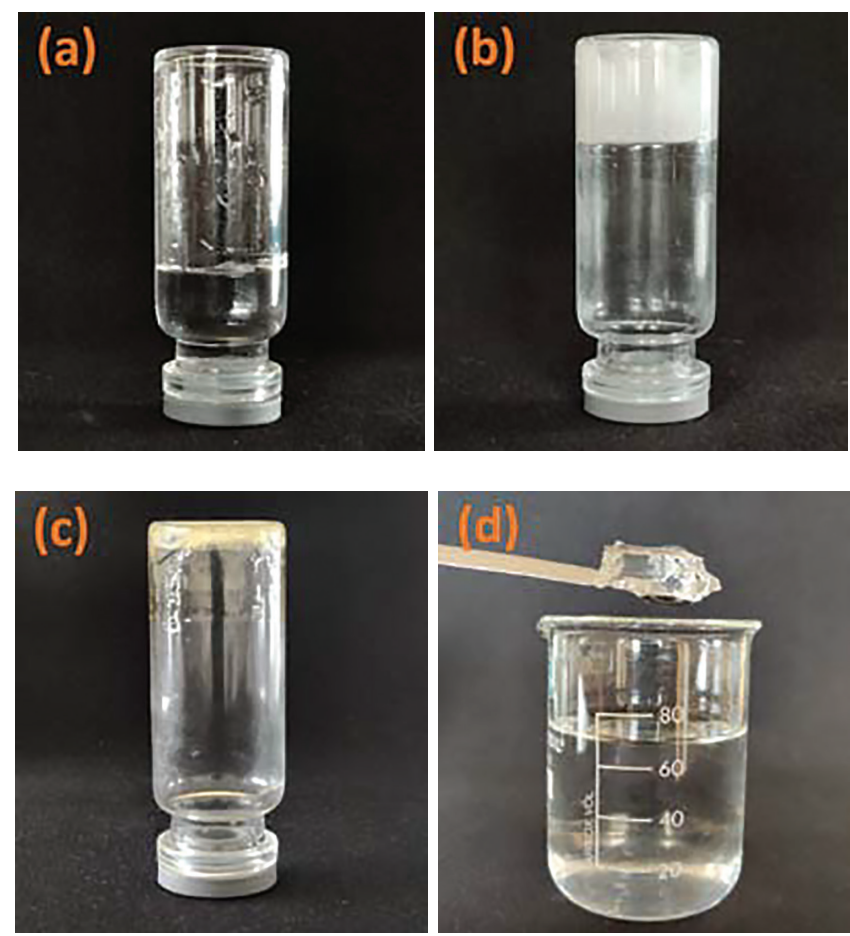

Figure 2. Preparation stages of hydrogel. (a) Initial stage in solution. (b) Gel shape. (c) Dryness. (d) Swelling.

$37^{\circ} \mathrm{C}$ and $27^{\circ} \mathrm{C}$ using paddle method in dissolution test apparatus (LabIndia, DS-8000, India), respectively. The release solution was withdrawn at regular time intervals (30 minutes) with a sufficient dilution scanning the solutions between 200 and $400 \mathrm{~nm}$ and $\lambda_{\text {max }}$ absorbance at $288 \mathrm{~nm}$ using a UV-Visible spectrophotometer was reported. The release percentage was determined and the zero-order, first-order, Higuchi, Korsmeyer-Peppas, and HixsonCrowell models were used to measure the statistical kinetic model of drug release (Baishya et al., 2017; Peppas et al., 2000).

$$
\text { Drug Loading }(\%)=\frac{W_{\mathrm{D}}-W_{0}}{W_{0}} \times 100
$$

where $W_{0}$ is the initial weight of the hydrogel and $W_{\mathrm{D}}$ is the weight of the drug-loaded hydrogel.

\section{Results and Discussion}

Using AAM and AAC as a monomer with MBA as a crosslinker, hydrogels were prepared. As free radical generators,

\begin{tabular}{|c|c|c|c|c|c|c|}
\hline \multirow{2}{*}{$\begin{array}{c}\text { Formulation } \\
\text { code }\end{array}$} & \multirow{2}{*}{ Water (ml) } & \multirow{2}{*}{ AAM (mg) } & \multirow{2}{*}{$\operatorname{AAC}(\mathrm{ml})$} & \multicolumn{2}{|c|}{ Initiator } & \multirow{2}{*}{ MBA $(m g)$} \\
\hline & & & & SMBS (mg) & PPS (mg) & \\
\hline AAMCH1 & 10 & 300 & 0.3 & 32 & 45 & 06 \\
\hline AAMCH2 & 10 & 300 & 0.3 & 32 & 45 & 11 \\
\hline AAMCH3 & 10 & 300 & 0.3 & 32 & 45 & 16 \\
\hline AAMCH4 & 10 & 300 & 0.3 & 32 & 45 & 21 \\
\hline
\end{tabular}

Table 1. Schemes for the synthesis of hydrogels. 
potassium persulfate and SMBS are used (Mahdavinia et al., 2004; Thippeswamy et al., 2021). The mechanism of the reaction is shown in Scheme 1 and the hydrogel formulations are given in Table 1.

\section{Hydrogel preparation}

Figure 2 shows the hydrogel preparation steps. The swelling analysis was conducted after gel preparation (Isik and Kis, 2004; Madhusudana et al., 2021; Teo et al., 2008).

\section{FTIR analysis}

Moxifloxacin hydrochloride FTIR spectra (Fig. 3a) showed aromatic $\mathrm{C}=\mathrm{C}$ stretching at $1,619 \mathrm{~cm}^{-1}$ and also demonstrated carboxylic acid $\mathrm{C}=\mathrm{O}$ stretching at $1,703 \mathrm{~cm}^{-1}, \mathrm{C}-\mathrm{N}$ stretching at

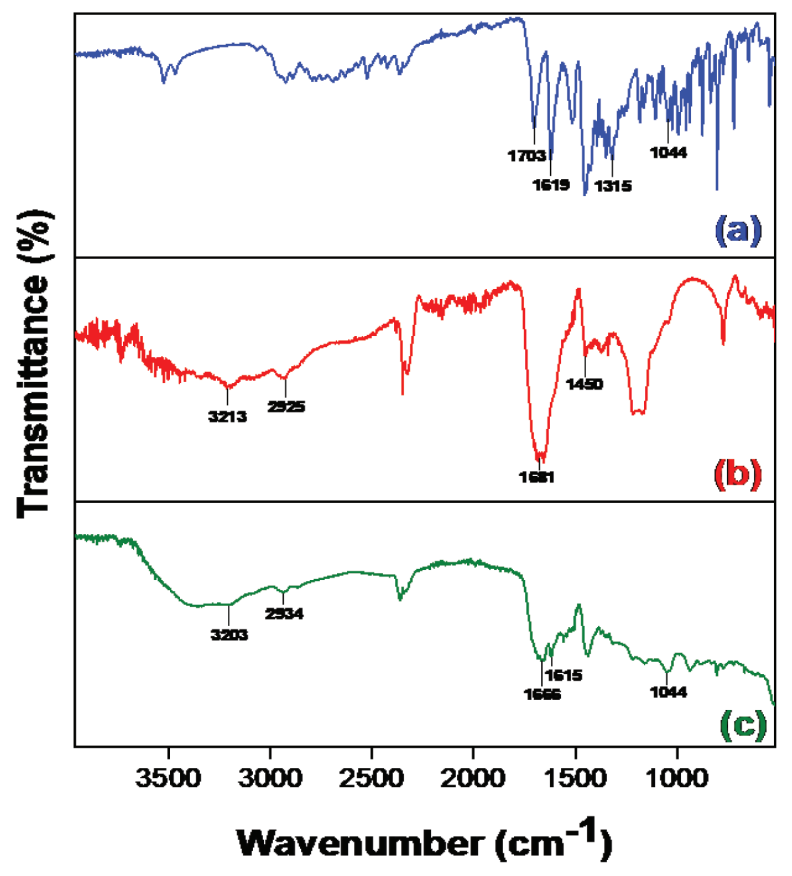

Figure 3. FTIR spectrum of (a) moxifloxacin, (b) poly(AAM-co-AAC) hydrogel, and (c) moxifloxacin-loaded hydrogel.

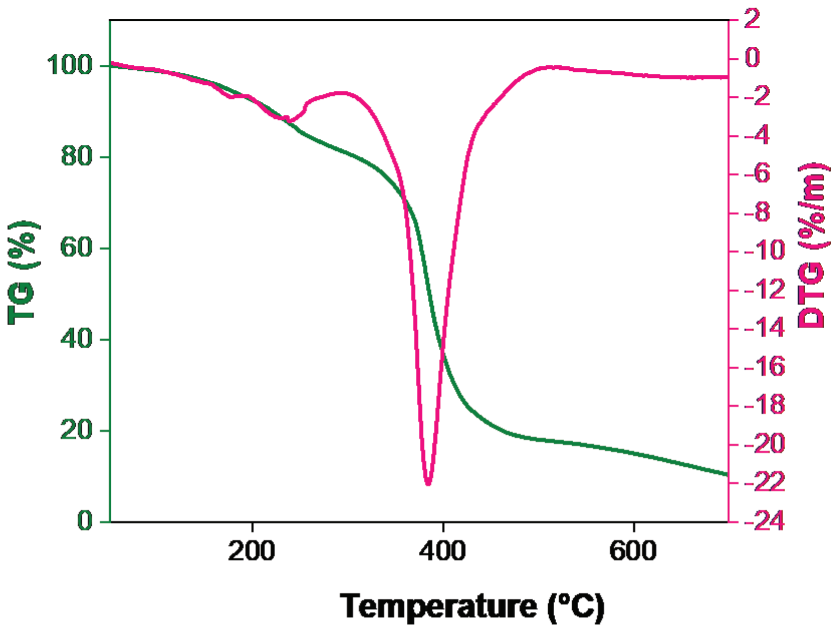

Figure 4. Poly(AAM-co-AAC) hydrogel TGA graph.
$1,315 \mathrm{~cm}^{-1}$, and monofluorobenzene stretching at $1,044 \mathrm{~cm}^{-1}$. The poly(AAM-co-AAC) hydrogel spectra (Fig. 3b) showed carboxylic acid stretching at $3,213 \mathrm{~cm}^{-1}$, corresponding to the $-\mathrm{OH} . \mathrm{CH}_{2}$ groups provided absorption at $1,450 \mathrm{~cm}^{-1}$ on the chain. The 2,925 $\mathrm{cm}^{-1}$ absorbance is the acrylate unit $\mathrm{C}-\mathrm{H}$ stretching. The absorption can be attributed to the $\mathrm{C}=\mathrm{O}$ group at $1,681 \mathrm{~cm}^{-1}$. The drug-loaded hydrogel peaks (Fig. 3c) observed were $3,203 \mathrm{~cm}^{-1}$, corresponding to the carboxylic acid $-\mathrm{OH}$ stretching. The $2,934 \mathrm{~cm}^{-1}$ absorbance is the $\mathrm{C}-\mathrm{H}$ stretching and $\mathrm{C}=\mathrm{O}$ group at $1,666 \mathrm{~cm}^{-1}$. Aromatic $\mathrm{C}=\mathrm{C}$ stretching was at $1,615 \mathrm{~cm}^{-1}$ and monofluorobenzene stretching was at $1,044 \mathrm{~cm}^{-1}$ (Pravin et al., 2012; Tomar et al., 2007).

\section{TGA analysis}

TGA has analyzed the thermal stability of the prepared hydrogel and the results are shown in Figure 4. Owing to the presence of moisture content in the hydrogel, the primary weight loss was absorbed. The poly(AAM-co-AAC) hydrogel was thermally unstable and degradation started at $240^{\circ} \mathrm{C}$ with a weight loss of $3.2 \%$ and a high mass loss was observed at $384^{\circ} \mathrm{C}$ with a weight loss of $22.0 \%$ due to breaking of crosslinking chain. This reduction has continued up to $700^{\circ} \mathrm{C}$ with a lesser amount (Ebrahimi and Salavaty, 2018).

\section{SEM Study}

The synthesized hydrogel micrographs (Fig. 5) were analyzed by SEM. The SEM Figures indicate that the surface is
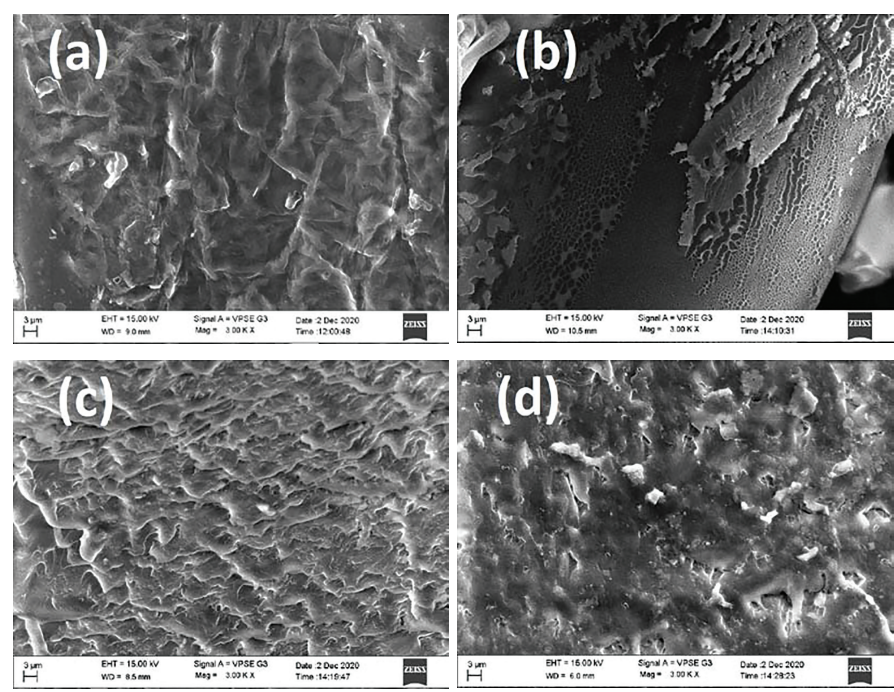

Figure 5. SEM images of the dried hydrogels. (a) AAMCH1. (b) AAMCH2. (c) AAMCH3. (d) AAMCH4.
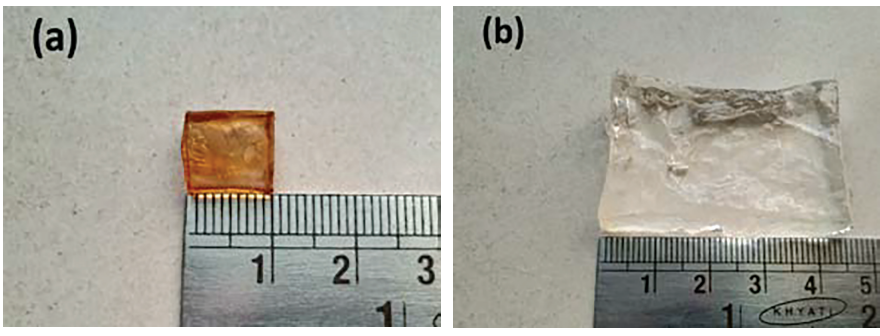

Figure 6. Images of (a) dried and (b) swollen hydrogels on a digital camera. 
hard and it has been found to be slightly porous (Aouada et al., 2009; Chen et al., 2009).

\section{Swelling study}

The swelling efficiency (Fig. 6) of the prepared hydrogel was studied using $\mathrm{pH} 1-10$ solutions. The swelling ratio decreased when the crosslinker increased the maximum swelling observed in AAMCH1 (Fig. 7). Hence, due to the maximum swelling ratio observed, we chose AAMCH1 for further swelling and drug release study. The swelling ratio of the hydrogel in $\mathrm{pH} 1.2$ and 7.4 buffer solutions similar to gastrointestinal fluids is shown in Figure 9. The results showed a high swelling ratio $(7258 \%)$, observed in $\mathrm{pH} 7.4$ compared to the solution at $\mathrm{pH} 1.2(115 \%)$. The $-\mathrm{CONH}_{2}$ groups are protonated at a lower $\mathrm{pH}$ to create $\mathrm{NH}^{3+}-\mathrm{NH}^{3+}$ electrostatic repulsion swelling, but its swelling will be decreased by the presence of chloride ions. Carboxylic acid $\mathrm{COOH}$ groups are deprotonated $\left(-\mathrm{COO}^{-}\right)$at higher $\mathrm{pH}$ and create electrostatic swelling repulsions, but the presence of more sodium ions $\left(\mathrm{Na}^{+}\right)$in $\mathrm{pH} 9$ and $\mathrm{pH} 10$ solutions reduces the swelling ratio

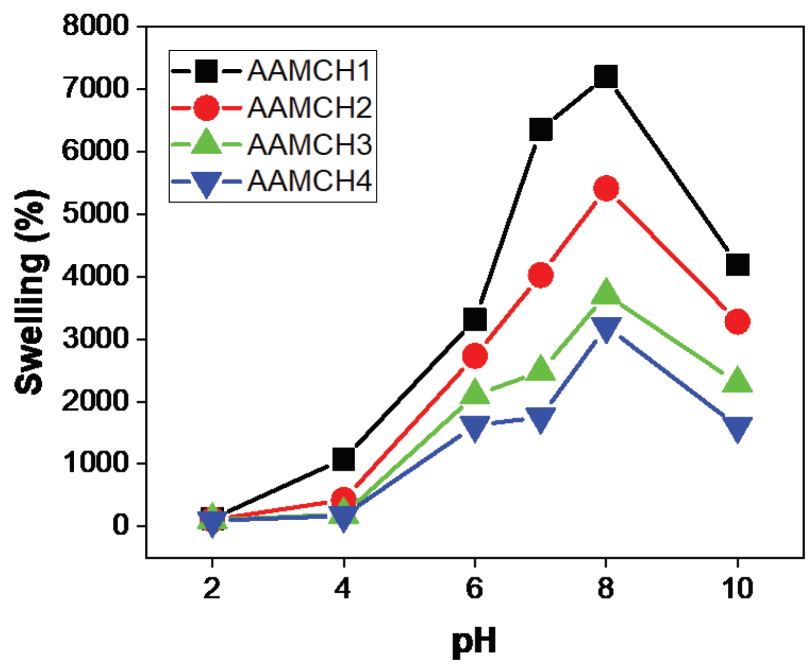

Figure 7. Hydrogel swelling ratio of different formulations.

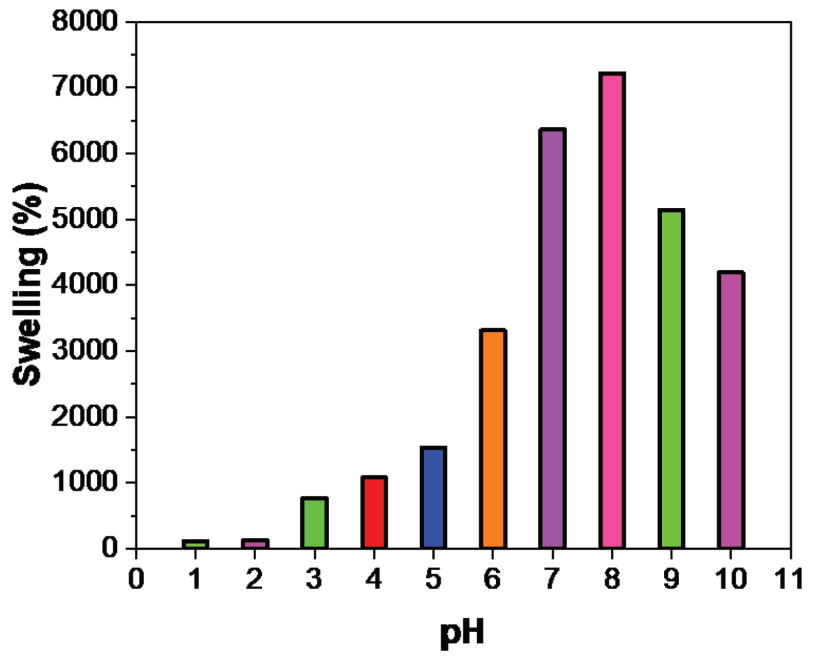

Figure 8. Hydrogel swelling ratio at $\mathrm{pH} 1-10$. compared to $\mathrm{pH} 8$ by forming -COONa group (Fig. 8) (Pourjavadi and Mahdavinia, 2006; Wu et al., 2001).

\section{Drug selection}

The selection of the drug for the release of the drug is most critical because to avoid $\lambda_{\max }$ change, the drug should not react with solvents and hydrogels. Moxifloxacin drug has excellent content since no difference in $\lambda_{\text {max }}$ has been observed as time shifts. In order to assess maximal absorption at $\lambda_{\text {max }} 288 \mathrm{~nm}$, solutions were scanned between 200 and $400 \mathrm{~nm}$ from the UVVisible spectrophotometer. The calibration curve (Figs. 12 and 13) shows that $R^{2}$ is 0.999 (coefficient of correlation).

\section{Drug release}

\section{Drug release with time}

The outcome of the swelling analysis helps assess the study of drug release. In acid and alkaline $\mathrm{pH}$, the swelling ratio in $\mathrm{pH} 1.2$ and 7.4 solutions (Fig. 9) suggest maximum swelling at alkaline pH 7.4 compared to $\mathrm{pH} 1.2$ solutions similar to gastrointestinal fluid-like solutions. The drug release percentage of moxifloxacin is maximum (99\%) at $\mathrm{pH} 7.4$ than at $\mathrm{pH} 1.2(18 \%)$ due to the swelling ratio maximum at $\mathrm{pH}$ 7.4. The hydrogel induces $\mathrm{pH}$-sensitive drug release at maximum $\mathrm{pH}$ of 7.4 than $\mathrm{pH} 1.2$ (Fig. 14).

\section{Drug release with temperatures}

The swelling ratio increased with increased temperature as compared to $27^{\circ} \mathrm{C}$ and $37^{\circ} \mathrm{C}$ (Fig. 10). To determine the temperature

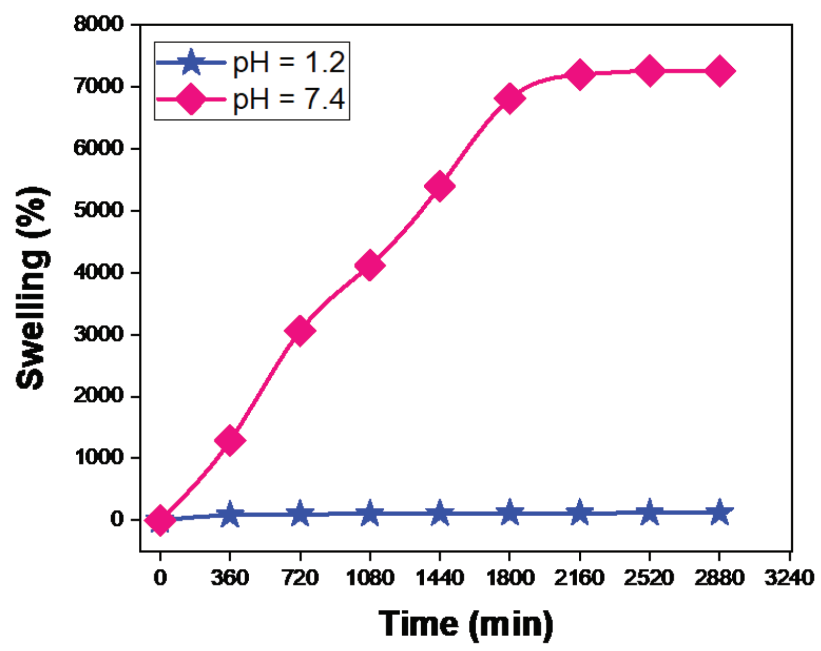

Figure 9. Hydrogel swelling ratio at $\mathrm{pH} 1.2$ and $\mathrm{pH}$ 7.4.

Table 2. Drug release results in terms of $R^{2}$, slope, and intercept of the different kinetic models.

\begin{tabular}{|c|c|c|c|}
\hline Name of the kinetic model & $\boldsymbol{R}^{\mathbf{2}}$ & Slope & Intercept \\
\hline Zero order & 0.967 & 19.79 & 10.61 \\
\hline First order & 0.636 & -0.506 & 2.458 \\
\hline Higuchi & 0.976 & 0.02 & 0.243 \\
\hline Korsmeyer-Peppas & 0.467 & 1.243 & 1.207 \\
\hline Hixson-Crowell & 0.934 & 0.767 & -0.282 \\
\hline \multicolumn{3}{|l}{}
\end{tabular}




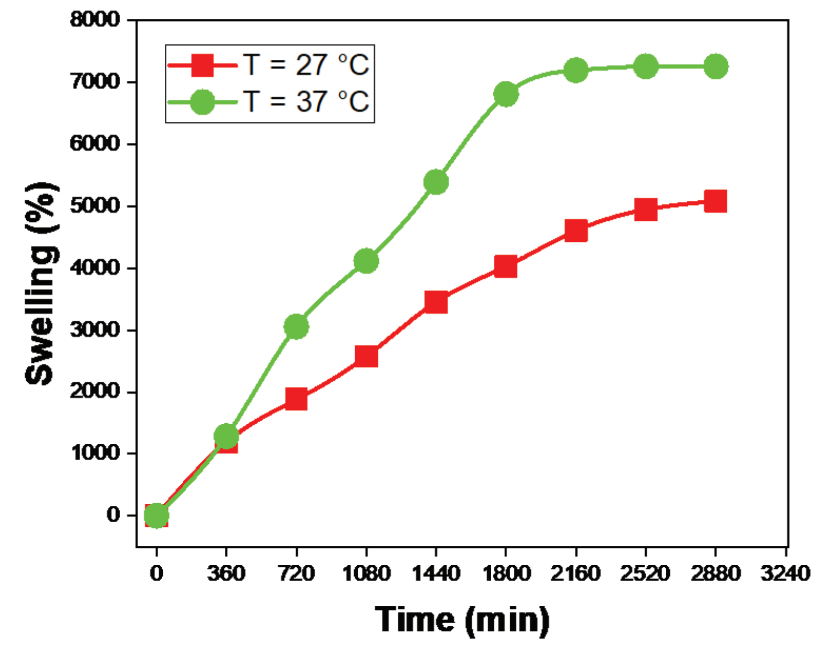

Figure 10. Hydrogel swelling ratio at temperatures of $27^{\circ} \mathrm{C}$ and $37^{\circ} \mathrm{C}$ in $\mathrm{pH} 7.4$ solution.

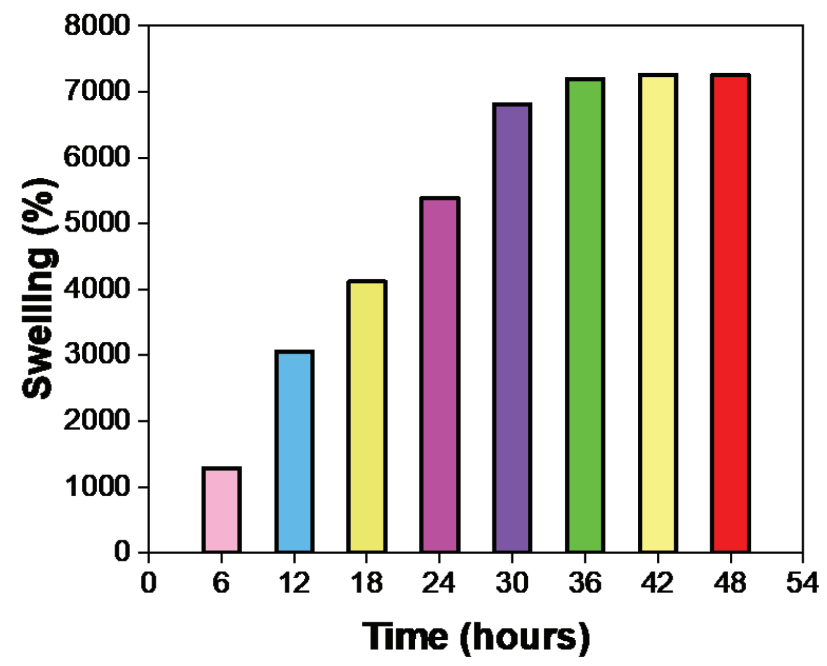

Figure 11. Changes in the swelling ratio over time in $\mathrm{pH}$ 7.4.

sensitivity of the hydrogel in drug release, we measured the $\mathrm{pH} 7.4$ solution at $27^{\circ} \mathrm{C}$ and $37^{\circ} \mathrm{C}$ temperatures over time (Fig. 15). The outcome indicates that drug release has increased with temperature changes. The minimum amount $(71 \%)$ of drug release was observed at $27^{\circ} \mathrm{C}$ and the maximum amount $(99 \%)$ of drug release was observed at $37^{\circ} \mathrm{C}$. The swelling ratio increases as the temperature increases due to the versatile nature produced in the polymer network, so water quickly enters the hydrogel network and swells. Similarly, the buffer solution enters the hydrogel polymer network and contributes to the increases in swelling and drug release.

\section{Kinetic model drug release}

The in-vitro release of the drug was estimated using different mathematical models and the effects of the correlation coefficient $\left(R^{2}\right)$ shown in Table 2 were evaluated. The maximum degree of the coefficient of correlation contributes to finding a suitable mathematical model that fits the kinetics of release. The result shows that the highest correlation coefficient $\left(R^{2}\right)$ is 0.976 , so the hydrogel fits the Higuchi model drug release.

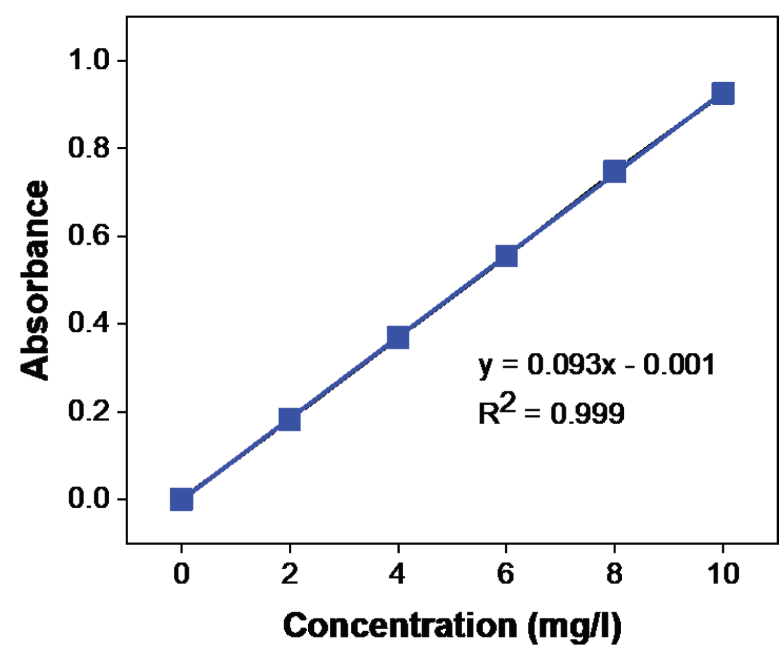

Figure 12. Moxifloxacin calibration curve (absorbance vs. concentration).

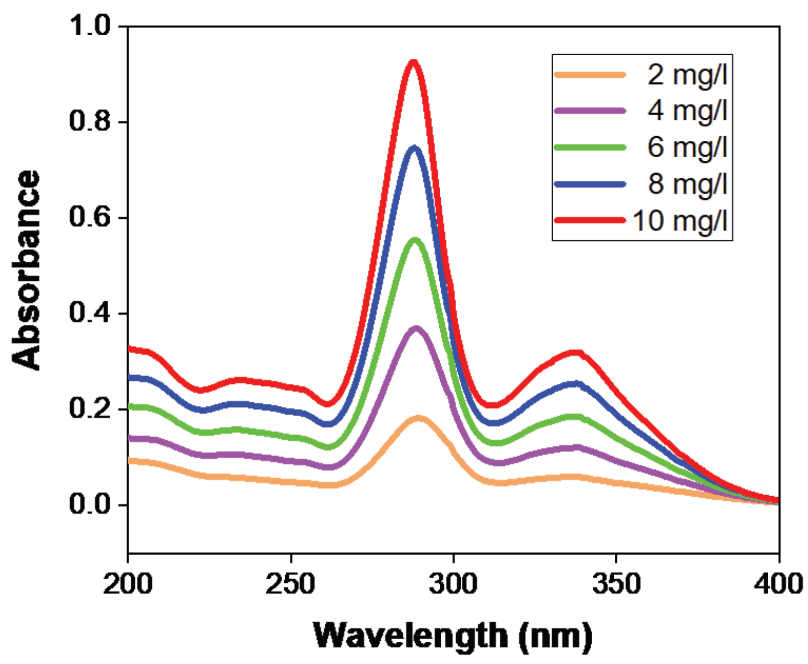

Figure 13. Moxifloxacin calibration curve spectral graph.

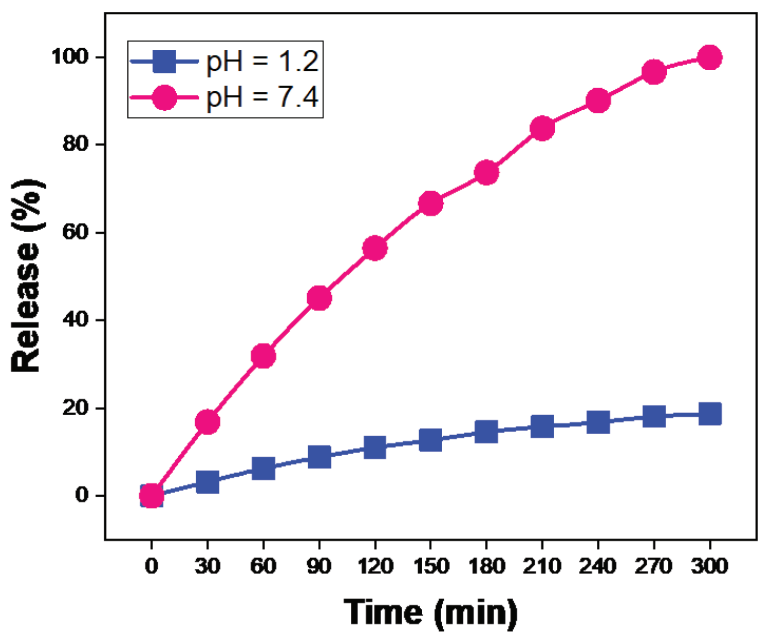

Figure 14. Release of moxifloxacin drug at $\mathrm{pH} 1.2$ and $\mathrm{pH} 7.4$ solutions over time. 


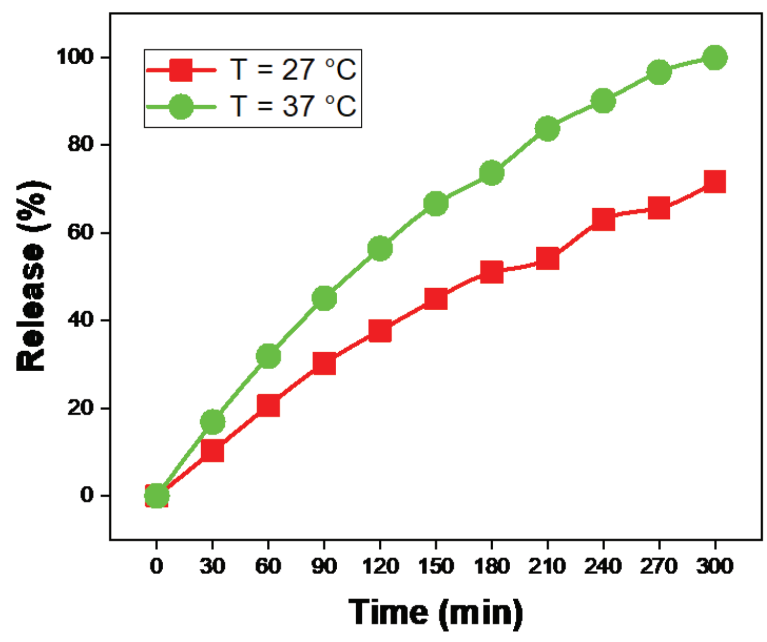

Figure 15. Release of moxifloxacin drug at varying temperatures over time.

\section{CONCLUSION}

By crosslinking with MBA as a crosslinker, poly(AAMco-AAC ) hydrogels were synthesized using SMBS and potassium persulfate as initiators. At different temperatures and $\mathrm{pH}$ levels, the swelling and drug release experiments were carried out. The outcome of the swelling analysis indicates maximum swelling at alkaline $\mathrm{pH}$ than acidic $\mathrm{pH}$, and the swelling ratio also increases as the temperature increases. Drug release experiments using moxifloxacin as a model drug have been conducted and the findings indicate maximum drug releases at $\mathrm{pH} 7.4$ compared to $\mathrm{pH}$ 1.2. Since the acid groups are deprotonated at $\mathrm{pH} 7.4$ and amide groups are protonated to generate electrostatic repulsion, this electrostatic repulsion allows the hydrogel to swell further; so more dissolution media entering the hydrogel enables further drug release. The effects of $\mathrm{pH}$ and temperature have also been studied as swelling increases in temperature and drug release also increases. This hydrogel follows the kinetic release of the Higuchi model and can be used in biomedical applications particularly for controlled drug delivery systems.

\section{ACKNOWLEDGMENT}

The authors are thankful to Micro Labs Limited, Bangalore, India, for gifting moxifloxacin hydrochloride.

\section{AUTHORS' CONTRIBUTIONS}

All authors made substantial contributions to the conception and design, acquisition of data, and analysis and interpretation of data; they took part in drafting the article and revising it critically for important intellectual content; agreed to submit to the current journal; gave final approval of the version to be published; and agreed to be accountable for all aspects of the work.

\section{CONFLICT OF INTEREST}

The authors declared no conflicts of interest regarding the publication of this article.

\section{FUNDING}

There is no funding to report.

\section{ETHICAL APPROVAL}

This study does not involve experiments on animals or human subjects.

\section{REFERENCES}

Aouada FA, Chiou BS, Orts WJ, Mattoso LH. Physicochemical and morphological properties of poly (acrylamide) and methylcellulose hydrogels: effects of monomer, crosslinker and polysaccharide compositions. Polym Eng Sci, 2009; 49:2467-74.

Baishya H, Gouda R, Qing Z. Application of mathematical models in drug release kinetics of carbidopa and levodopa ER tablets. J Dev Drugs, 2017; 06:1-8.

Biedenbach DJ, Jones RN. The comparative antimicrobial activity of levofloxacin tested against 350 clinical isolates of Streptococci. Diagn Microbiol Infect Dis, 1996; 25:47-51.

Charoo NA, Abdallah DB, Parveen T, Abrahamsson B, Cristofoletti R, Groot DW, Langguth P, Parr A, Polli JE, Mehta M, Shah VP, Tajiri T, Dressman J. Biowaiver monograph for immediate-release solid oral dosage forms: moxifloxacin hydrochloride. J Pharm Sci, 2020; 109:2654-75.

Chen J, Liu M, Liu H, Ma L. Synthesis, swelling and drug release behavior of poly $(\mathrm{N}, \mathrm{N}$-diethylacrylamide-co-N-hydroxymethyl acrylamide) hydrogel. Mater Sci Eng C, 2009; 29:2116-23.

Dalhoff A, Petersen U, Endermann R. In-vitro activity of Bay 12-8039, a new 8-methoxyquinolone. Chemotherapy, 1996; 42:410-25.

Davis R, Bryson HM. Levofloxacin: a review of its antibacterial activity, pharmacokinetics and therapeutic efficacy. Drugs, 1994; 47:677-700.

Ebrahimi R, Salavaty M. Controlled drug delivery of ciprofloxacin from ultrasonic hydrogel. e-Polymers, 2018; 18:187-95.

Imming P, Sinning C, Meyer A. Drugs, their targets and the nature and number of drug targets. Nature Rev Drug Discovery, 2006; 5:821-34.

Isik B, Kis M. Preparation and determination of swelling behavior of poly(acrylamide-co-acrylic acid) hydrogels in water. Appl Polym Sci, 2004; 94:1526-31.

Madhusudana T, Mamatha GP, Demappa T, Satyanarayan ND Controlled drug release of levofloxacin from poly (acrylamide) hydrogel. Int J Res Pharm Sci, 2021; 12(2):1037-43.

Thippeswamy M, Puttagiddappa MG, Thippaiah D, Satyanarayan N. Synthesis and characterization of poly(acrylamide) hydrogels as $\mathrm{pH}$ and salt sensitive material. Asian J Chem, 2021; 33(5):1019-24.

Mahdavinia G, Pourjavadi A, Hosseinzadeh H, Zohuriaan M. Modified chitosan 4. superabsorbent hydrogels from poly (acrylic acid-coacrylamide) grafted chitosan with salt-and $\mathrm{pH}$-responsiveness properties. Eur Polym J, 2004; 40:1399-407.

Moghimi SM, Hunter. Poloxamers and poloxamines in nanoparticle engineering and experimental medicine. Trends Biotechnol, 2000; 18:412-20.

Peppas NA, Bures P, Leobandung W, Ichikawa H. Hydrogels in pharmaceutical formulations. Eur J Pharm Biopharm, 2000; 50:27-46.

Peppas NA. Hydrogels and drug delivery. Curr Opin Colloid Interface Sci, 1997; 2:531-7.

Peppas NA, Khare AR. Preparation, structure and diffusional behavior of hydrogels in controlled release. Adv Drug Deliv Rev, 1993; $11: 1-35$.

Peppas NA, Langer R. New challenges in biomaterials. Science, 1994; 263:1715-20.

Pestova E, Millichap JJ, Noskin GA, Peterson LR. Intracellular targets of moxifloxacin: a comparison with other fluoroquinolones. J Antimicrob Chemother, 2000; 45:583-90.

Pourjavadi A, Mahdavinia GR. Superabsorbency, pH-Sensitivity and swelling kinetics of partially hydrolyzed chitosan-g-poly(Acrylamide) hydrogels. Turk J Chem, 2006; 30:595-608.

Pravin KP, Rajesh K, Dipak KM. Design and evaluation of moxifloxacin hydrochloride ocular inserts. Acta Pharm, 2012; 62:93-104. 
Ratner BD, Hoffman AS. Hydrogels for medical and related applications. Am Chem Soc, 1976; 31:1-36.

Reece RJ, Maxwell A. DNA gyrase: structure and function. Crit Rev Biochem Mol Biol, 1991; 26:335-75.

Shah N, Patel KR. Formulation and development of hydrogel for poly acrylamide-Co-acrylic acid. J Pharm Sci Biosci Res, 2014; 4:114-20.

Teo BM, Prescott SW, Ashokkumar M, Grieser F. Ultrasound initiated miniemulsion polymerization of methacrylate monomers. Ultrason Sonochem, 2008; 15:89-94.

Tomar RS, Gupta I, Singhal R, Nagpal AK. Synthesis of poly (acrylamide-co-acrylic acid) based superabsorbent hydrogels: study of network parameters and swelling behaviour. Polym Plast Technol Eng, 2007; 46:481-8.

Varaprasad K, Raghavendra GM, Jayaramudu T, Yallapu MM, Sadiku R. A mini review on hydrogels classification and recent developments in miscellaneous applications. Mater Sci Eng C, 2017; 79:958-71.

Vinu R, Madras G. Photocatalytic degradation of poly(acrylamide-co-acrylic acid). J Phys Chem B, 2008; 112:8928-35.
Wu J, Lin J, Li G, Wei C. Influence of the $\mathrm{COOH}$ and $\mathrm{COONa}$ groups and crosslink density of poly (acrylic acid)/montmorillonite superabsorbent composite on water absorbency. Polym Int, 2001; 50:1050-3.

How to cite this article:

Madhusudana T, Mamatha GP, Demappa T, Satyanarayan ND. Poly(acrylamide-co-acrylic acid) synthesized, moxifloxacin drug-loaded hydrogel: Characterization and evaluation studies. J Appl Pharm Sci, 2021; 11(12):074-081. 